\title{
Effects of Light Curing Method and Exposure Time on Mechanical Properties of Resin Based Dental Materials
}

\author{
A. Rıza Alpöza , DDS, PhD \\ Fahinur Ertuḡrul ${ }^{b}, \mathrm{DDS}, \mathrm{PhD}$ \\ Dilsah Coguluc, DDS, PhD \\ Aslı Topaloḡlu Akc, DDS, PhD \\ Metin Tanoḡlud, PhD \\ Elçin Kaya ${ }^{\mathrm{e}}$
}

\section{ABSTRACT}

Objectives: The aim of this study was to investigate microhardness and compressive strength of composite resin (Tetric-Ceram, Ivoclar Vivadent), compomer (Compoglass, Ivoclar, Vivadent), and resin modified glass ionomer cement (Fuji II LC, GC Corp) polymerized using halogen light (Optilux 501, Demetron, Kerr) and LED (Bluephase C5, Ivoclar Vivadent) for different curing times.

Methods: Samples were placed in disc shaped plastic molds with uniform size of $5 \mathrm{~mm}$ diameter and $2 \mathrm{~mm}$ in thickness for surface microhardness test and placed in a diameter of $4 \mathrm{~mm}$ and a length of $2 \mathrm{~mm}$ teflon cylinders for compressive strength test. For each subgroup, 20 samples for microhardness $(n=180)$ and 5 samples for compressive strength were prepared $(n=45)$. In group 1 , samples were polymerized using halogen light source for 40 seconds; in group 2 and 3 samples were polymerized using LED light source for 20 seconds and 40 seconds respectively. All data were analyzed by two way analysis of ANOVA and Tukey's post-hoc tests.

Results: Same exposure time of 40 seconds with a low intensity LED was found similar or more efficient than a high intensity halogen light unit ( $P>.05)$, however application of LED for 20 seconds was found less efficient than 40 seconds curing time ( $P=.03$ ).

Conclusions: It is important to increase the light curing time and use appropriate light curing devices to polymerize resin composite in deep cavities to maximize the hardness and compressive strength of restorative materials. (Eur J Dent 2008;2:37-42)

Key words: Microhardness; Compressive strength; LED; Halogen light.

\footnotetext{
a Professor, Ege University, School of Dentistry, Department of Paediatric Dentistry, Izmir, Turkey.

b Assoc. Professor, Ege University, School of Dentistry, Department of Paediatric Dentistry, Izmir, Turkey. Research Asistant, Ege University, School of Dentistry, Department of Paediatric Dentistry, Izmir, Turkey.

d Professor, Izmir Institute of Technology, Department of Machine Engineering, Izmir, Turkey. e Research Asistant, Izmir Institute of Technology, Department of Machine Engineering, Izmir, Turkey.

- Corresponding Author: Dr. Aslı Topaloḡlu Ak Ege University, School of Dentistry, Department of Paediatric Dentistry, Izmir, 35100, Turkey Phone: + 9023238864 31, Fax: + 902323880325 E-mail: aslitopalogludyahoo.com
}

\section{INTRODUCTION}

In recent years the popularity of tooth coloured restorative materials has promoted a rapidly increasing use of resins. Composite resins, polyacid modified resin based composites (compomer) and resin modified glass ionomers (RMGIC) are most commonly used light polymerizable restorative materials. Composite resins are recommended for use mostly in permanent teeth whereas compomers and RMGIC are preferred in primary teeth and non-stress bearing cavities in permanent teeth as well. ${ }^{1,2}$ 
Light polymerizable restorative materials are most widely preferred for advantages such as esthetics, improved physical properties and operator's control over the working time..$^{3-7}$ Since the introduction of these light polymerizable restorative materials, there has been a concern about the depth of appropriate cure throughout the restoration. Moreover, the significant role of effective polymerization in long-term clinical success of resin restorations has been well defined. ${ }^{8}$ Studies revealed that inadequate polymerization can contribute to a variety of clinical conditions such as discoloration, pulpal irritation, post-operative sensitivity and eventual failure of restoration. ${ }^{9}$ Factors affecting the polymerization of the resins include those directly related to restorative material including shade, thickness during polymerization and composition of the material. Light intensity, wavelength, exposure duration, size, location and orientation of the tip of the source are the factors related to light curing units. ${ }^{10,11}$

Halogen lights are the most commonly used devices for the polymerization of resin based dental materials. This low cost technology device have drawbacks such as decline of irradiance over time due to bulb and filter ageing which could lead to inadequate polymerization of resin. ${ }^{12-14}$ Different technologies for light curing resin based materials have been developed to overcome these problems.

The first light emitting diode (LED) light curing units were introduced marketing in 2001 as an alternative to halogen lamps. LEDs are highly efficient light sources that produce light within a narrow spectral range. Overtime only little degradation of light output is observed and they do not produce heat. This may be another advantage for avoiding any possible gingival or pulpal irritation. ${ }^{11}$ LED is very popular among paediatric dentists particularly, since less chair time and an adequate polymerization is the main goal. ${ }^{15}$

The purpose of this study was to evaluate the microhardness and compressive strength of a composite resin, a compomer and a resin modified glass ionomer polymerized with halogen and LED light curing unit. The null hypothesis to be tested was that microhardness and compressive strength of restorative materials is influenced by curing time and curing method.

\section{MATERIALS AND METHODS}

A light-cured hybrid composite (Tetric Ceram, Ivoclar Vivadent AG, Bendererstrasse, Liechtenstein), a compomer (Compoglass, Ivoclar Vivadent) and a RMGIC (Fuji II LC, GC Corporation, Tokyo, Japan) were evaluated. Materials used in this study are listed in Table 1.

A halogen light (Optilux 501,0P, Kerr Corp, Orange, CA, USA) and a LED unit (LED Bluephase C5, Ivoclar, Vivadent AG) were used. Technical details of the halogen and LED light-curing units are shown in Table 2.

For each material, 60 disc-shaped specimens (5 $\mathrm{mm}$ diameter and $2 \mathrm{~mm}$ thickness) in $\mathrm{A} 4$ shade were prepared using plastic molds for microhardness measurement. The specimens were then divided randomly into nine subgroups

Table 1. The tested materials with their compositions, specifications and manufacturers.

\begin{tabular}{l|c|c|c|c}
\hline Materials & $\begin{array}{c}\text { Filler content } \\
\text { (wg } \%)\end{array}$ & Particle size & Batch number & Manufacturer \\
\hline Tetric Ceram & $80 \%$ & $0.04-3.0 \mu \mathrm{m}$ & A20310 & $\begin{array}{r}\text { Ivoclar Vivadent AG, Bendererstrasse, } \\
\text { Liechtenstein }\end{array}$ \\
\hline Compoglass & $77.3 \%$ & $1.0 \mu \mathrm{m}$ & D51387 & $\begin{array}{r}\text { Ivoclar Vivadent AG, Bendererstrasse, } \\
\text { Liechtenstein }\end{array}$ \\
\hline Fuji II LC & $58 \%$ & $4.5 \mu \mathrm{m}$ & 110331 & GC Corporation, Tokyo, Japan \\
\hline
\end{tabular}

Table 2. Technical details of the light-curing units used in this study.

\begin{tabular}{llcl}
\hline Light Curing Units & Wavelength & Intensity & Manufacturer \\
\hline Optilux 501 & $400-515 \mathrm{~nm}$ & $700 \mathrm{mw} / \mathrm{cm}^{2}$ & Demetron, Kerr \\
LED Bluephase C5 & $430-490 \mathrm{~nm}$ & $500 \mathrm{mw} / \mathrm{cm}^{2}$ & Ivoclar Vivadent \\
\hline
\end{tabular}


according to light curing method and exposure time $(n=180)$

The restorative materials were handled according to the manufacturers' instructions. The molds were placed on flat glass plates on top of acetate strips and then filled with resin based material. The material was covered with an acetate strip and gently pressed with another glass plate against the mold to extrude excess material. The distance between the light source and sample was standardized by using a $1 \mathrm{~cm}$ glass plate. The light tip was in close contact with the restoration surface during polymerization. All specimens were prepared in a temperature controlled room at $23 \pm 1{ }^{\circ} \mathrm{C}$. Immediately after light-curing, the cover glasses were removed from the mold and the lower surfaces were marked with a pen and stored in the dark container in distilled water at $37^{\circ} \mathrm{C}$ for 7 days to maximize post polymerization prior to microhardness and compressive strength testing.

\section{Vickers hardness (VHN)}

Microhardness measurements of top surfaces of the specimens were determined by Vickers Hardness Testing Machine (Buehler, Lake Bluff, ILL, USA). The Vicker's surface microhardness test method consisted of indenting the test material with a diamond tip, in the form of a right pyramid with a square base and Vickers microhardness readings were undertaken using a load of $50 \mathrm{~g}$ for 20 seconds. Three indentations were made at random on each specimen and a mean value was calculated.

\section{Compressive strength}

The compressive strength measurements were recorded on teflon cylindirical specimens with a diameter of $4 \mathrm{~mm}$ and a thickness of $2 \mathrm{~mm}$. Five specimens for each above mentioned 9 subgroups were prepared as described previously $(n=45)$. The compression tests were implemented with a constant cross-head speed of $0.5 \mathrm{~mm} \mathrm{~min}^{-1}$ on a mechanical test machine (Material Test SystemMTS 810, MTS System Corp., Eden Prairie, Minn., USA).

All data were analyzed statistically by two way analysis of variance and Tukey's post-hoc tests.

\section{RESULTS}

\section{Vicker's hardness}

The mean microhardness values $( \pm S D$ ) of tested restorative materials are presented in Figure 1. Among tested resin based restorative materials, composite showed highest microhardness values which was statistically different from those compomer and RMGIC for all the curing methods $(P=.03)$. However no significant difference was detected between the compomer and RMGIC groups.

For composite, LED 40 seconds provided higher microhardness values than LED 20 seconds cured groups and halogen $40(\mathrm{P}=.02)$ whereas no significant difference was found between these two groups. The highest microhardness values for compomer were observed in LED polymerization for 40 seconds followed by halogen for 40 seconds and LED for 20 seconds respectively $(P=.04)$. The RMGIS had the highest microhardness values when polymerized with halogen for 40 seconds followed by LED for 40 seconds and 20 seconds, respectively. However, there was no significant difference in microhardness values of RMGIS polymerized with halogen and LED for 40 seconds. A significant difference was detected between halogen 40 seconds and LED 20 seconds cure groups $(P=.03)$.

\section{Compressive strength}

The results of the compressive strength values are presented in Figure 2. The results indicated that, among tested resin based restorative materials, the composite had significant lower compressive strength compared to composite and the compomer $(P=.03)$, whereas no significant difference was noted between the composite and compomer groups.

There was no significant difference in compressive strength of Tetric Ceram when polymerized with halogen for 40 second and LED 40 second, however LED 20 second cure group was found significantly lower $(P=.02)$. Compoglass showed the highest compressive strength for LED 40 second and 20 second curing respectively this was followed by halogen for 40 seconds $(P=.04)$. There was no significant difference found among three curing methods for RMGIC. 


\section{DISCUSSION}

The performance of biomaterials is most frequently evaluated using laboratory tests. ${ }^{16}$ One such parameter is surface microhardness that evaluates material surface resistance to plastic deformation by penetration. By means of this test an indirect measurement of the degree of conversion can be estimated as well. Top and bottom surface hardness of materials are still of concern. Some studies showed differences between top and bottom surface hardness. ${ }^{2,17,18}$ However, there are also studies revealing no significant difference indicating the sufficient energy penetration through the material. 15,19,20 Although, it has been suggested to evaluate both top and bottom surfaces of the materials, only the top surface of the specimens were tested in the current study since the recommended thickness of resins is $2 \mathrm{~mm}$.

Since the introduction of LED devices in restorative dentistry, there has been an increased interest in comparing their ability with regular halogen lamps. ${ }^{21}$ In the present study composite resin and compomer had the highest microhardness values when polymerized with LED for $40 \mathrm{~s}$ which indicated that LED $40 \mathrm{~s}$ group provided better polymerization than halogen 40 $s$ and LED 20 s cured group. On the other hand, for RMGIC halogen $40 \mathrm{~s}$ and LED $40 \mathrm{~s}$ cured groups provided similar extent of polymerization. However a significant difference was noted between halogen $40 \mathrm{~s}$ and LED 20 s cured groups. This indicated that halogen light and LED unit produced similar extent of polymerization for the resin modified glass ionomer group. In contrast to composite and compomer groups, surface

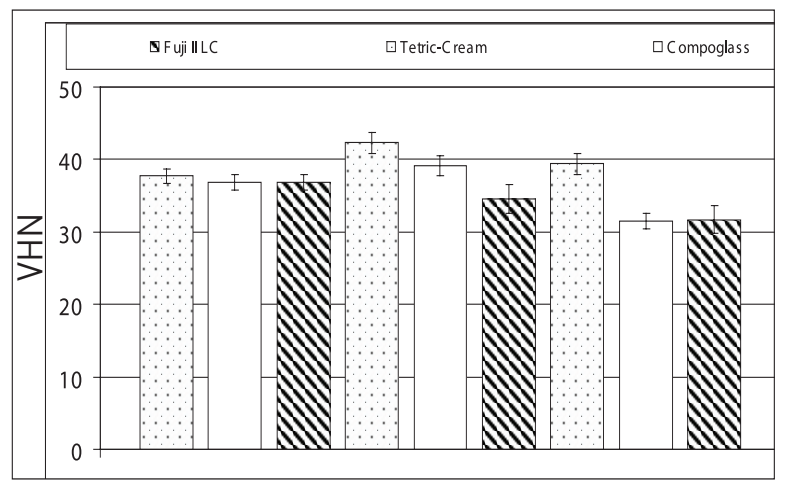

Figure 1. Mean VHN values and standard deviations for composite resin, compomer, and resin modified glass ionomer cement polymerized with different curing methods and exposure time. hardness of RMGIC did not change with the different exposure time with LED. The possible explanation is that polymerization of a resin is affected by characteristics inherent to the specific material being cured. ${ }^{22,23}$

Compressive strength is another test which is used to evaluate the mechanical properties of restorative materials. Since most of the mastication forces are compressive in nature, it is important to test long term performance of the restorative materials under this condition. In the current study, Tetric Ceram had the highest compressive strength values followed by Compoglass but the difference was not statistically significant. This could be attributed to similar percantage of filler particules in their compositions. The RMGIC showed statistically significant lower compressive strength compared to composite and the compomer due to differences in filler particles of the resin based materials affecting the mechanical properties. $^{24}$

It is well defined that mechanical properties of light-polymerized dental materials is dependent on the polymerization condition, light intensity, wavelength and exposure time which are critical variables for achievement of maximum curing. ${ }^{25-30}$ In our study we compared the efficiency of a high intensity halogen light unit to low intensity LED by evaluating surface hardness and compressive strength of a composite resin, compomer and a resin modified glass ionomer. The light output for halogen was $700 \mathrm{~mW} / \mathrm{cm}^{2}$ whereas for LED was $500 \mathrm{~mW} / \mathrm{cm}^{2}$. In contrast to previous generations of LED lights, higher light intensity of the newer LED devices with their narrow spectral output makes them even more efficient than conventional

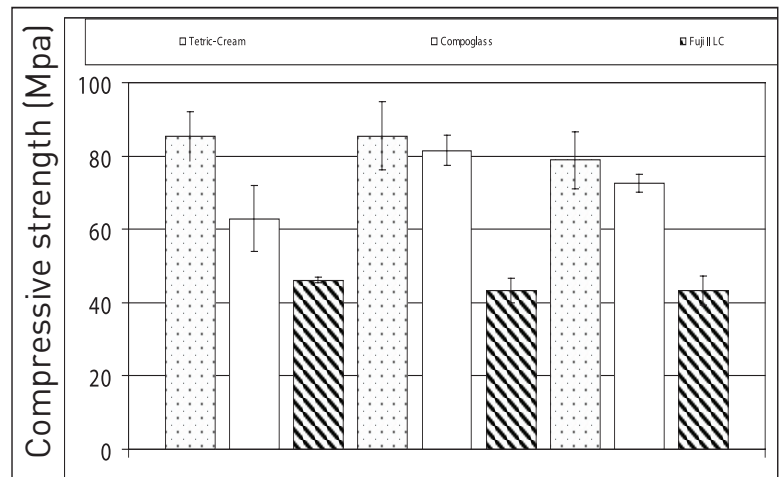

Figure 2. Compressive strength (means and standard deviations) for composite resin, compomer, and resin modified glass ionomer cement polymerized with different curing methods and exposure time. 
halogen light-curing units. ${ }^{31,32}$

The objective of the study was to determine the mechanical properties of commercially available composite resin, compomer and a resin modified glass ionomer by means of microhardness and compressive strength following polymerization with a halogen and a LED light unit. Results of the present study led to an acceptance of the null hypothesis. It has been indicated that in the current study same exposure time of 40 seconds with a low intensity LED was similar or more efficient than a high intensity halogen light unit. However application of LED for $20 \mathrm{~s}$ was less efficient than 40 s curing time according to microhardness and compressive strength tests.

\section{CONCLUSIONS}

On the basis of these results, superiority of LED units over halogen light is still debatable when different resin based dental restorative materials are polymerized. It should also be kept in mind that different mechanical test should be applied individually or in combination with other test in order to determine mechanical properties of dental restorative materials. It is important to increase the light curing time and use appropriate light curing devices to polymerize resin composite in deep cavities to maximize the hardness and compressive strength of restorative materials.

\section{REFERENCES}

1. McLean JW, Nicholson JW, Wilson AD. Proposed nomenclature of glass- ionomer dental cements and related materials. Quintessence Int 1994;25:587-589.

2. Rosenstiel SF, Land MF, Crispin BJ. Dental luting agents: A review of the current literature. J Prosthet Dent 1998;80:280301.

3. David JR, Gomes OM, Gomes JC, Loguercio AD, Reis A. Effect of exposure time on curing efficiency of polymerizing units equipped with light-emitting diodes. J Oral Sci 2007;49:19-24.

4. Dietschi D, Marret N, Krejci I. Comparative efficiency of plasma and halogen light sources on composite microhardness in different curing conditions. Dent Mater 2003;19:493-500.

5. Geurtsen W, Spahl W, Leyhausen G. Residual monomer/ additive release and variability in cytotoxicity of lightcuring glass-ionomer cements and compomers. J Dent Res 1998;77:2012-2019.

6. Geurtsen W, Leyhausen G, Garcia-Godoy F. Effect of storage media on the fluoride release and surface microhardness of four polacid modified composite resins (compomers). Dent Mater 1999;15:1196-1201.

7. Kwon YH, Kwon TY, Ong JL, Kim KH. Light polymerized compomers: coefficient of thermal expansion and microhardness. J Prosthet Dent 2002;88:396-401.

8. Nomoto R, Uchida K, Hirasawa T. Effect of light intensity on polymerization of light-cured composite resins. Dent Mater $J$ 1994;13:198-205.

9. Price RB, Derand T, Lonev RW, Andreou P. Effect of light source and specimen thickness on the surface hardness of resin composite. Am J Dent 2002;15:47-53.

10. McCabe J, Carrick TE. Output from visible-light activation units and depth of cure of light-activated composites. $J$ Dent Res 1989;68:1534-1539.

11. Leonard DL, Charlton DG, Roberts HW, Cohen ME. Polymerization efficiency of LED curing lights. $J$ Esthet Restor Dent 2002;14:286-295.

12. Dunn WJ, Bush AC. A comparison of polymerization by light-emitting diode and halogen based light curing units. $J$ Am Dent Assoc 2002;133:335-341.

13. Hammesfahr PD, O'Connor MT, Wang X. Light curing technology : Past, present and future. Compend Contin Educ Dent 2002;23:18-24.

14. Mills RW, Jandt KD, Ashworth SH. Dental composite depth of cure halogen and blue light emitting diode technology. Br Dent J 1999;186:388-391.

15. Okte Z, Villalta P, Garcia-Godoy F, Garcia-Godoy F Jr., Murray $P$. Effect of curing time and light curing systems on the surface hardness of compomers. Oper Dent 2005; 30:540-545

16. Besnault C, Attal JP. Simulated oral environment and microleakage of Class II resin based composite and sandwich restorations. Am J Dent 2003:16:186-190.

17. Garcia-Godody F Jr, Garcia-Godoy A, Garcia-Godoy F Composite hardness ratio: Effect of different LED curing systems IADR/AADR/CADR 82 ${ }^{\text {nd }}$ General Session, 2004; March 10-13

18. Jandt KD, Mills RW, Blackwell GB, Ashworth SH. Depth of cure and compressive strength of dental composites cured with blue light emitting diodes (LEDs). Dent Mater 2000;16:41-47.

19. Leonard DL, Charlton DG, Roberts HR, Hilton TJ, Zionic A. Determination of the minimum irradiance required for adequate polymerization of a hybrid and a microfill composite. Oper Dent 2001;26:176-180.

20. Peutzfeld A, Garcia-Godoy F, Asmussen E. Surface hardness and wear of glass ionomers and compomers. Am J Dent 1997;10:15-17.

21. Caughman WF, Rueggeberg FA, Curtis JW Jr. Clinical 
guidelines for photocuring restorative resin. $J$ Am Dent Assoc 1995;126:1280-1282.

22. Feilzer AJ, Dooren LH, de Gee AJ, Davidson CL. Influence of light intensity on polymerization shrinkage and integrity of restoration-cavity interface. Eur J Oral Sci 1995;103:322326.

23. Martin FE. A survey of the efficiency of visible light curing units. J Dent 1998;26:239-243.

24. Leinfelder KF. Using composite resin as a posterior restorative material. J Am Dent Assoc 1991;22:65-70.

25. Hoffmann N, Markert T, Hugo B, Klaiber B. Effect of high intensity vs. soft-start halogen irradiation on light-cured resin-based composites. Part II: Hardness and solubility. Am J Dent 2004;17:38-42.

26. Kurachi C, Tuboy AM, Magalhaes DV, Bagnato VS. Hardness evaluation of a dental composite polymerized with experimental LED-based devices. Dent Mater 2001;17:309315.

27. Wiggins KM, Hartung M, Althoff O, Wastian C, Mitra SB. Curing performance of a new-generation light-emitting diode dental curing unit. $J$ Am Dent Assoc 2004;135:14711479.

28. Suzuki S, Leinfelder KF, Kawai K, Tsuchitani Y. Effect of particle variation on wear rates of posterior composites. Am J Dent 1995;8:173-178.

29. Van Noort R. Introduction to dental materials. London: Mosby Co, $1^{\text {st }}$ ed, 1997:89-102.

30. Cavalcante LM, Peris AR, Amaral CM, Ambrosano GM, Pimenta LA. Influence of polymerization technique on microleakage and microhardness of resin composite restorations. Oper Dent 2003;28:200-206.

31. Soh MS, Yap AU, Siow KS. Effectiveness of composite cure associated with different curing modes of LED lights. Oper Dent 2003;28:371-377.

32. Rueggeberg FA, Caughman WF, Curtis JW Jr, Davis HC. Factors affecting cure at depths within light-activated resin composites. Am J Dent 1993;6:91-95. 